\title{
Holistic Approach to Smart Buildings from Construction Material to Services
}

\author{
Essam Eldin Khalil \\ Department of Mechanical Engineering, Cairo University, Cairo, Egypt \\ Email: Khalile1@asme.org
}

Received September 28, 2012; revised October 26, 2012; accepted November 30, 2012

\begin{abstract}
This paper presents a recent status quo of HVAC airside design for the air-conditioned spaces under holistic approach. The present review summarizes the current status, future requirements, and expectations. It has been found that, the experimental investigations should be considered in the new trend of energy investigations, not to merely to validate the numerical tools, but also to provide a complete database of the airflow characteristics in the air-conditioned spaces. Based on this analysis and the vast progress of computers and associated software, the artificial intelligent technique is sought as a prominent competitor candidate to the experimental and numerical techniques. Finally, the researches that relate between the different designs of the HVAC systems and energy consumption should concern with the optimization of airside design as the expected target to enhance the indoor environment.
\end{abstract}

Keywords: HVAC Design; Energy Efficiency; Air Quality; Comfort

\section{Introduction}

In attempts to adequately design an optimum HVAC airside system that furnishes comfort and air quality in the air-conditioned spaces with efficient energy consumption is a great challenge. Air conditioning identifies the conditioning of air for maintaining specific conditions of temperature, humidity, and dust level inside an enclosed space. The conditions to be maintained are dictated by the need for which the conditioned space is intended and comfort of users. So, the air conditioning embraces more than cooling or heating. The comfort air conditioning is defined as "the process of treating air to control simultaneously its temperature, humidity, clean liness, and distribution to meet the comfort requirements of the occupants of the conditioned space" [1]. Air conditioning, therefore, includes the entire heat exchange operation as well as the regulation of velocity, thermal radiation and quality of air, as well as the removal of foreign particles and vapours. Achieving occupant comfort and health is the result of a collaborative effort of environmental conditions, such as: Indoor air temperature; relative humidity; airflow velocity; pressure relationship; air movement efficiency; Contaminant concentration; Illumination and visual comfort; and sound and noise; and other factors.

In the holistic approach, the totality of the effects of the heat sink and sources in the building and the technical building systems that are recoverable for space conditioning, are typically considered in the calculation of the thermal energy needs.

As the technical building thermal systems losses depend on the energy input, which itself depends on the recovered system thermal sources, iteration might be required.

The calculation procedure can be devised as follows:

1) Sub-system calculations are first performed as per prevailing standards and that will be followed by determination of the recoverable thermal system losses;

2) The recoverable thermal system losses are then added to the other recoverable heat sources already included (e.g. solar and internal heat gains, recoverable thermal losses from lighting and/or other technical building systems like domestic hot water) in the calculation of the needs for heating and cooling;

3) Thermal energy needs for heating and cooling are then recalculated;

4) Iterations are performed from step 1 until the calculated changes of the energy needs between two successive iterations are less than a defined limit (e.g. 1\%) or stop calculations after a specified number of iterations;

5) Continue to calculate the difference between the energy at the start of the iterations and the end; these are the recovered system thermal losses.

\section{Comfort Levels}

\subsection{Preamble}

Thermal comfort is that condition of mind that expresses 
satisfaction with the thermal environment. Because there are large variations, both physiologically and psychologically, from person to person, it is difficult to satisfy everyone in a space. The environmental conditions required for comfort are not the same for everyone. Extensive laboratory and field data have been collected that provide the necessary statistical data to define conditions that a specified percentage of occupants will find thermally comfortable. Section 5 of this standard is used to determine the thermal environmental conditions in a space that are necessary to achieve acceptance by a specified percentage of occupants of that space. There are six primary factors that must be addressed when defining conditions for thermal comfort. A number of other, secondary factors affect comfort in some circumstances [1].

The temperature regulatory centre in the brain is about $36.8^{\circ} \mathrm{C}$ at rest in comfort and increases to about $37.4^{\circ} \mathrm{C}$ when walking and $37.9^{\circ} \mathrm{C}$ when jogging [1]. High temperatures may cause increased out gassing of toxins from furnishings, finishes, building materials, etc. Alternatively, ambient temperatures that are too cool can cause occupant discomfort such as shivering, inattentiveness, and muscular and joint tension. Relative humidity plays an important role in the comfort feeling, which affects the comfort feeling directly or indirectly by its influence on the temperature. Excessive relative humidity levels are known to reduce human comfort. Most of guidelines specify the range (35\% to $50 \%$ ) as the optimum conditions for the relative humidity. The airflow pattern plays an important role in the comfort sensation and also in the scavenging of the hazards and airborne particles. According to the results of researches and the standards specifications, the optimum airflow velocity falls within the range of $(0.2 \mathrm{~m} / \mathrm{s}$ to $0.25 \mathrm{~m} / \mathrm{s})$ in the occupied zone.

\subsection{Problem Identification}

Many of the HVAC applications suffer from the poor distribution of the indoor air temperature and relative humidity as well as the incorrect airflow velocities. This poor distribution arises from the poor airflow distribution and the presence of the thermal drift due to the buoyancy effect.

\subsection{Status Quo}

In the present time, most of researches recommend the experimental and numerical simulation as the perfect tools to obtain the optimum design. The optimization procedure of the HVAC airside design depends on the predictions of the air temperature distribution based on the simulation of different parametric designs using experimentally verified numerical tools. The influence of various ventilation strategies and vapour generation rate on the characteristics of temperature and moisture distri- bution is investigated [2]. The vast majority of the available thermal comfort data pertains to sedentary or near sedentary physical activity levels typical of office work. The body of available data does not contain significant information regarding the comfort requirements of children, the disabled, or the infirm.

Airside design and room furnishing were found influential in order to ensure a comfortable environment, especially in the displacement ventilation configuration [2]. The airflow velocity influence was investigated, and it was found that the velocity could be accepted to be as high as $0.35 \mathrm{~m} / \mathrm{s}$ in the occupied zone [3]. The configurations of the conditioned space affect the comfort level as well as the space applications, such as the healthcare facilities, which are so complex $[4,5]$. The correct specifications of outdoor ambient conditions affect thermal loads, as shown in Figure 1, and consequently the comfort level [6]. Some researches recommend changing the focus on the effect of building envelope to reduce the thermal load to enhance the thermal comfort [7].

\subsection{Closure}

The comfort conditions depend on many factors beyond the indoor air temperature, relative humidity, and airflow velocity. Comfort conditions depend also on the air distribution pattern and the air movement [8], but the effect of these factors can be considered close to the air quality more than the comfort level. Indeed, the comfort criteria affect the air quality and the energy conservation in the ventilated and conditioned spaces, as shown in the following sections. The relation between the comfort and air quality is an interchange or mutual relation.

\section{Air Quality}

\subsection{Preamble}

Most of guidelines consider the air quality is the result of a collaborative effort of environmental conditions those presented in the introduction section. Indeed, in the present literature the air quality is specified by the result of a collaborative effort of the pressure relationship, air movement efficiency, and contaminant concentration. These conditions play an important role to achieve the optimum air quality. Simply, design of ventilation system must, as much as possible, provide air movement from the clean to the less-clean areas. This rule requires a great careful to design the airside system and to select the design of airside system of the neighbourhoods. There are relative interactions between the conditioned neighbouring spaces. The air distribution and movement efficiency can be considered as the indicator of the comfort and air quality simultaneously. There are several important considerations that characterize the air distribution in airconditioned spaces, namely first, the flow is generally 


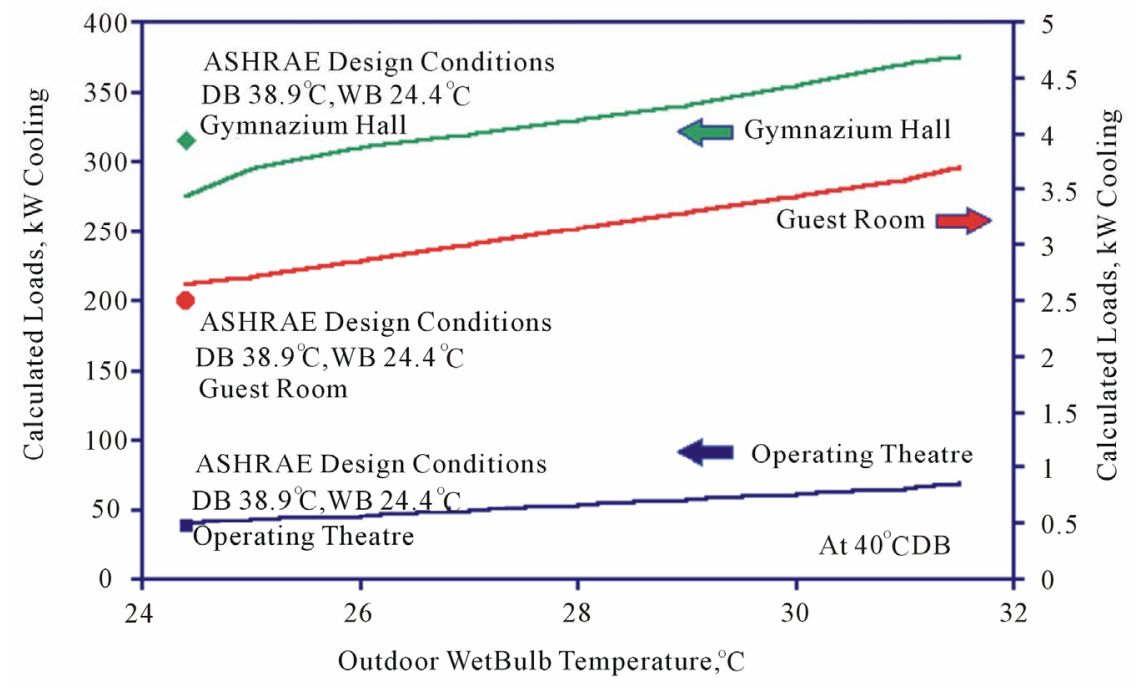

Figure 1. Outdoor conditions and thermal loads.

turbulent and buoyancy effects are often significant. Then the transverse transport effects are of particular interest in these flows. Combined heat and mass transfer processes prevail in that case and coupled transport mechanisms are generally present. Undesirable airflow between rooms and floors is often difficult to control because of open doors, movement of staff and patients, temperature differentials, and stack effect. While some of these factors are beyond practical control, the effect of others may be minimized by terminating shaft openings in enclosed rooms and by designing and balancing air systems to create positive or negative air pressure within certain rooms and certain areas.

Contaminants can be classified in four broad headings, each of which represents a wide variety of pollutants; Organic \& Inorganic Compounds; Particulate Matter; and Biological Contaminants. It should be understood that these classifications are intended to facilitate the categorization of contaminants. Although the pollutants are classified into these categories, certain contaminants may belong to two or more classifications, depending upon their nature. The classification of organic compounds represents chemical compounds that contain carbon-hydrogen bonds in their basic molecular structure. Their sources can be either natural products or synthetics; especially those derived from oil, gas, and coal. Organic contaminants may exist in the form of gas (vapour), liquid or as solid particles in the atmosphere, food and/or water. Inorganic compounds are those which do not contain carbon-hydrogen bonds in their molecular structure.

The danger of particulate matter is their ability to become contaminated by other ambient sources, increasing health risks to individuals who are exposed to Respirable Suspended Particles (RSP). Particles following into this category are, usually, less than $10 \mathrm{~mm}$ in aerodynamic diameter. As mentioned previously, particles smaller than $5 \mathrm{~mm}$ are capable of bypassing the respiratory defences. Biological contaminants are generally referred to as microbes or micro organisms. Biological contaminants are minute particles of living matter produced from a variety of sources. The variety of biological compounds that may be present in the ambient environment is immense. Sources of pollution exist in both the internal and external environment. The air quality is controlled by removal of the contaminant or by dilution. ASHRAE [1] prescribes both necessary quantities of ventilation for various types of occupancies and methods of determining the proportions of outside air and recirculated air. If the level of contaminants in outdoor air exceeds that for minimum air quality standards, extraordinary measures must be used. Although proper air conditioning designs are helpful in the prevention and treatment of diseases, the application of air conditioning to health facilities presents many specific problems. Those are not encountered in the conventional comfort conditioning design.

\subsection{Problem Identification}

The contaminant concentration mainly depends on the two factors, air pressure relationship, and the air movement efficiency. So the optimum design of these two factors leads to accepted concentration and safe distribution of the contaminant. Actually, most of guidelines, known to date, don't restrict any airside design for each application. This gives a large tolerance and many designs alternatives, which are not totally perfect.

\subsection{Status Quo}

The comfort and air quality is investigated with the aid of experimental and numerical techniques, to represent the relation between the thermal conditions and the air qual- 
ity [9]. It was found that thermal conditions affect the air quality and therefore any recommended the numerical models should account for balanced thermal conditions. This would affect the discrepancies between measured and simulated results and consequently create a more generalized numerical formula of the air characteristics. The effect of thermal loads and cooling strategies on the airflow pattern in an office was investigated by applying mixing ventilation, [10] as well as those results indicating the effect of supply conditions on the airflow pattern [4]. The ventilation performance takes a great place in the last decades, which represents the capabilities of the airside design on providing a clean space. The effect of the heat and contaminant source location on the ventilation performance was also considered. It was found that the optimum ventilation performance is achieved when these sources are located near the exhaust opening [11]. The air quality is generally influenced by airborne and contaminant generation in the healthcare applications, especially in the critical sites such as the isolation and surgery rooms. Several researches investigated the airborne particle control in the operating rooms using the numerical techniques [12-15].

\subsection{Closure}

Air movement efficiency is mainly based on two factors, which are; the air pressure relationship with the other neighbourhood spaces, and the airside design. Differential air pressure can be maintained only in an entirely sealed room. Therefore, it is important to obtain a reasonably close fit of all doors and seal all walls and floor penetrations between pressurized areas. This is best accomplished by using weather stripping and drop bottoms on doors. The opening of a door between two areas instantaneously reduces any existing pressure differential between them to such a degree that its effectiveness is nullified. When such openings occur, a natural interchange of air takes place between the two rooms due to turbulence created by the door opening and closing combined with personal ingress/egress.

\section{Energy Efficient Buildings Design}

\subsection{Preamble}

Energy crisis in the early 1970s forced the development of energy conserving strategies in a variety of industries. Sustainability and energy efficiency continue to be strong issues in this time of limited resources. Therefore, the implementation of energy conserving strategies in the HVAC systems must be balanced with occupant comfort and health. Few guidelines gave specific recommendations about the energy saving in the HVAC systems, but these recommendations don't meet all requirements and design varieties. Indeed, in the hot and humid climate the outdoor conditions play important role in the energy consumption.

\subsection{Problem Identification: Pyramid Concept}

Till now, the guidelines and design standards don't provide restricted utilization strategies of the conditioned air in the spaces. Indeed, this situation creates several inefficient systems and consequently expensive energy invoice. In some critical facilities, such as hospitals, HVAC designers face the problem of balancing between the healthy conditions and the energy utilization. The assessment of the overall energy performance of a particular building, including the technical building systems, comprises a number of successive steps, which can be schematically visualized as a pyramid. Figure 2 indicated the various items into energy performance of buildings.

\subsection{Status Quo}

The relation between the HVAC system designs and the optimum conditions and optimum energy utilization is still under investigation up today. In recent researches [16], the effect of ventilation design on the comfort and energy utilization is investigated. The effect of the displacement ventilation on humidity gradient in a factory located in the hot and humid region was illustrated [16]. It was found the strong dependence relation between the correct supplying conditions and comfort. Indeed, the displacement ventilation is recommended as an energy efficient system, however, the created humidity and temperature gradient, because this system gives the designers the suitable tolerance to select more economize supply conditions. In recent years, new design traditions of the ventilation systems, such as the under-floor ventilation systems are growing to overcome the problems of the current systems. The under-floor air supply is recommended as an alternative to the ceiling air supply in the office buildings to overcome the lack of flexibility in the ceiling systems and to improve the comfort conditions $[16,17]$. It is noticeable that those who advised the under-floor system recommend it due to its capability to reduce the energy consumption due to the operational characteristics of supplied air.

\subsection{Closure}

As the optimization of the energy consumption is new trend, the achievement of this level needs new investigation trend in the scientific researches. Actually, the energy utilization mainly depends on the optimum utilization of the conditioned air in the conditioned spaces. Sets of common terms, definitions and symbols are essential for all segments from top to bottom. These cover terms such as energy needs, technical building systems, 


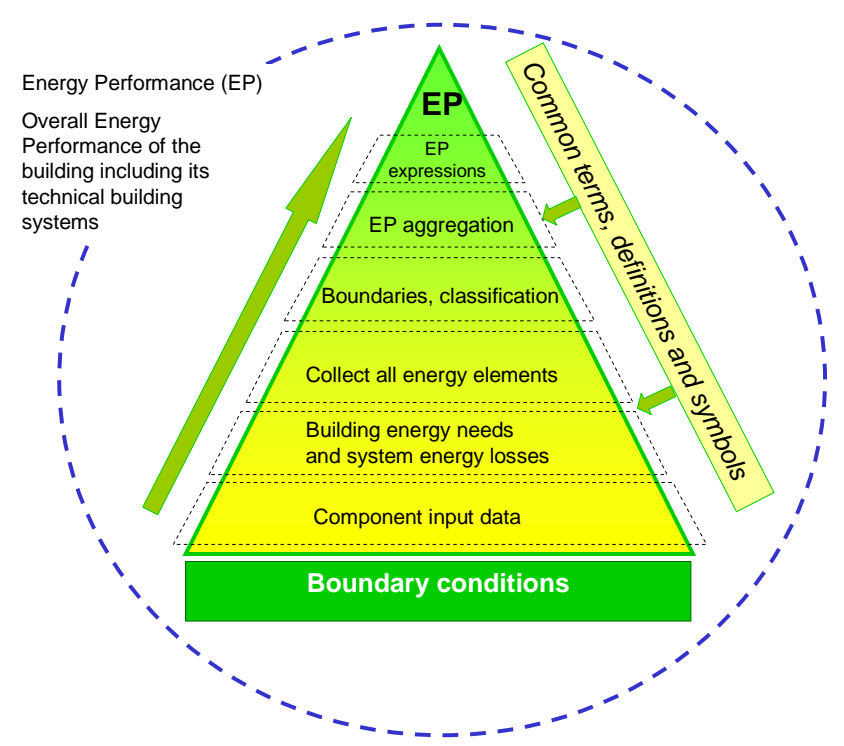

Figure 2. Overall building energy performance indications.

auxiliary energy use, recoverable system losses, primary energy and renewable energy.

\section{Air Conditioning System Design of Commercial Buildings}

In theory, if properly applied, every system can be successful in any building. However, in practice, such factors as initial and operating costs, space allocation, architectural design, location, and the engineer's evaluation and experience limit the proper choices for a given building type. Heating and air-conditioning systems should be: simple in design and, of proper size for a given building, of generally fairly low maintenance; of low operating costs; of optimum inherent thermal control as is economically possible. Such control might include materials with high thermal properties, insulation, and multiple or special glazing and shading devices.

An example of Commercial buildings applications is provided here for libraries and museums.

In general, libraries have storage areas, working and office areas, a main circulation desk, reading rooms, rare book vaults, and small study rooms. In general, museums would have exhibit areas, work areas, back offices, and storage areas. Some larger museums may have souvenir shops, a restaurant or cafeterias, etc.

\subsection{Load Characteristics}

Many libraries, especially college libraries, operate up to $12 \mathrm{~h}$ per day and may run the air conditioning equipment about 4200 h per year. Such constant usage requires the selection of heavy duty, long-life equipment, which requires little maintenance. Museums are generally open about 8 to $10 \mathrm{~h}$ per day, 5 to 7 days per week. The ambi- ent conditions should not vary in temperature or relative humidity. The conditions should remain constant $24 \mathrm{~h}$ per day, year-round. Cold or hot walls and windows, and hot steam or water pipes should be avoided. Object humidity may be destructive, even if the ambient relative humidity is under control.

Sun Gain. Libraries and museums usually have windows, sometimes of stained glass, and skylights-more in traffic areas, than in book stacks or storage areas. Care must be taken to minimize the effects of the sun; shortwave (actinic) rays are particularly injurious. Heat gain from skylights, often over artificially lighted frosted glass ceilings, can be reduced by a separate forced ventilation system.

Transmission. In winter, effects on objects located close to outside walls and possible condensation of moisture on the objects and the surface of outside walls must be evaluated. In summer, possible radiant effects from exposure should be considered.

People. Some areas may have concentrations as high as $1.0 \mathrm{~m}^{2}$ per person, while office space will have closer to 10 or $15 \mathrm{~m}^{2}$ per person, and book stack areas up to 100 $\mathrm{m}^{2}$ per person.

Lights. Careful analyses of the required lighting intensity should be made in various rooms and in view of day lighting availability.

Stratification. In reading rooms, large entrance halls, and large art galleries with high natural or false ceilings, air temperature may stratify.

\subsection{Design Concepts}

All-air ducted systems are preferred in library public areas, careful evaluation of relative humidity is essential. This is also true for museums, because exhibit items are 
generally irreplaceable. In museums, people loads vary, depending on whether there is a new exhibit, the time of day, weather, and other factors. Thus, individually controlled zones are required to maintain optimal environmental conditions. Attempts to establish a modular system for partitions have been only partially successful because of the wide range of sizes of items in the exhibits. In art museums, particularly, partitions may create local pockets with hot air supply or exhaust; transfer grilles may be placed in the partitions to obtain some air flow movement. Another problem is the location of room thermostats and humidistats.

\subsection{Special Considerations}

Many old manuscripts, books and artifacts have been damaged or destroyed because they were not kept in a properly air-conditioned environment. The need for better preservation of such valuable materials, together with a rising popular interest in the use of libraries and museums, requires that most of them, whether new or existing, be air-conditioned. Air-conditioning problems for museums and libraries are generally similar, but differ in design concept and application. Figure 3 depicts an example of artifacts deterioration due to excessive humidity, Khalil [18].

\subsection{Design Criteria}

In an average library or museum, less stringent design criteria are usually provided than for archives, because the value of the books and collections does not justify the higher initial and operating costs. Low-efficiency air filters are often provided. Relative humidity is held below 55\%. Room temperatures are held within the $20^{\circ} \mathrm{C}$ to $21.5^{\circ} \mathrm{C}$ range. Archival libraries and museums should have $85 \%$ or better air filtration, a relative humidity of $35 \%$ for books, and temperatures of $16^{\circ} \mathrm{C}$ in book stacks and $20^{\circ} \mathrm{C}$ in reading rooms.

\subsection{Building Contents}

Museums contents and collections reaction to room conditions should be carefully considered and critically examined. For example, paper used in books and manuscripts prior to the eighteenth century is very stable and is not significantly affected by the room environment. For archival preservation, this paper should be stored at very low temperatures. It is estimated that for each $5^{\circ} \mathrm{C}$ dry bulb the room temperature is lowered, the life of the paper will double, and that any humidity reduction will also lengthen the life of paper.

\subsection{Effect of Ambient Atmosphere}

The temperature and, particularly, the relative humidity of the air have a marked influence on the appearance, behaviour, and general quality of hygroscopic materials such as paper, textiles, wood, and leather, because the moisture content of these substances comes into equilibrium with the moisture content of the surrounding air. The object humidity is usually defined as the relative humidity of the thin film of air in close contact with the surface of an object and at a temperature cooler or warmer than the ambient dry bulb. If artifacts are permitted to cool overnight, the next day they will be enveloped by layers of air having progressively higher relative humidities. These may range from the ambient of 45 to $60 \%$ to $97 \%$ immediately next to the object surface, thus effecting a change in material regain or even condensation. This, combined with the hygroscopic or salty dust often found on objects recovered from excavations, can be destructive.

\subsection{Sound and Vibration}

Air-conditioning equipment should be treated with sound and vibration isolation to ensure quiet comfort for visitors and staff as per the ASHRAE standards and local environmental laws.

\section{Evaluation Indices}

\subsection{Preamble}

The evaluation indices of the comfort, air quality, and energy utilization efficiency can be divided to two main categories, empirical indices based on the experimental techniques, and numerical indices based on the numerical techniques. The most common indices provide the required evaluation of the air characteristics at individual positions (or in other scope, at individual points) in the indoor environment.

\subsection{Problem Identification}

Until now, the evaluation of the comfort, air quality, and energy utilization efficiency performed only at individual position (locally evaluation). Still there is no general global evaluation index for several characteristics such as the airflow movement and the contaminant concentration and its influence on the occupancy health. Actually, the air flow distribution pattern plays the role of global evaluation index up today. On the other hand, there is noglobal evaluation index capable of evaluating comfort, air quality, and energy utilization efficiency simultaneously. Actually, this global index will aid the HVAC designers to achieve the optimum design according to the optimum indoor air quality levels [19,20].

\subsection{Status Quo}

Energy efficiency is better characterised in buildings through the energy efficiency ratio EER. An index that is 

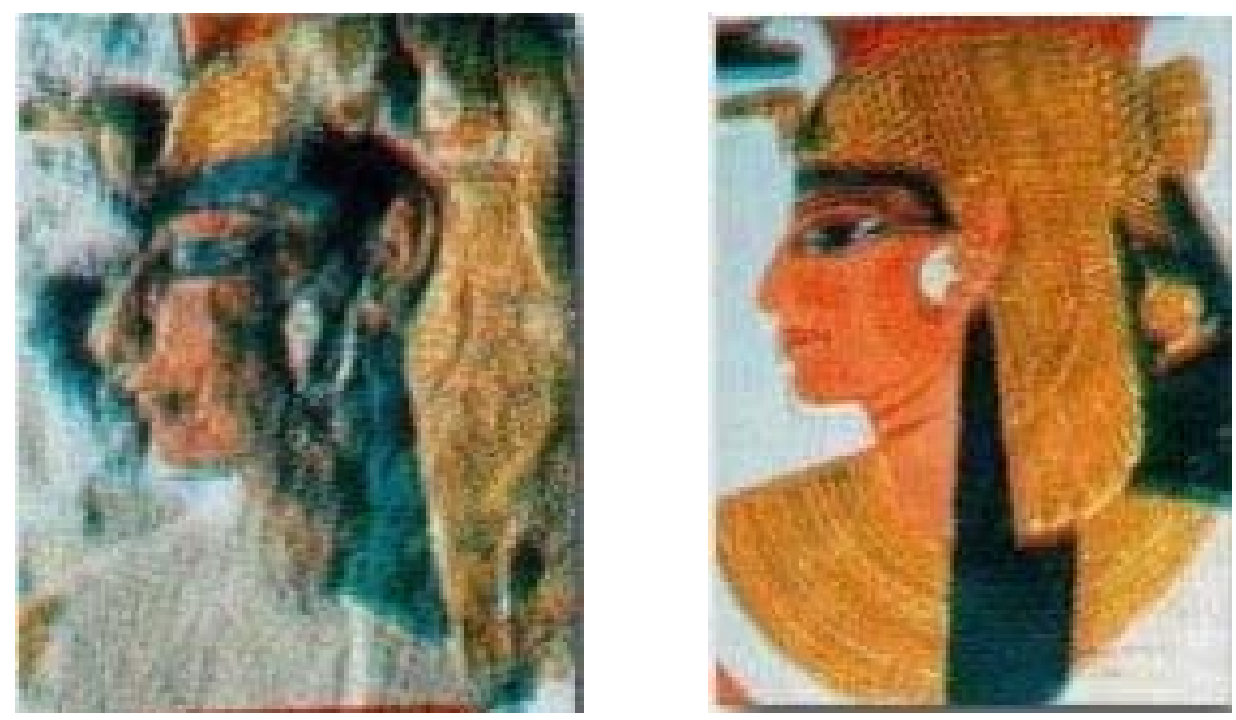

Figure 3. Effect of moisture content in the colour of artifacts.

mandatory in all air conditioning and refrigeration system. Defined as the useful output divided by the energy input, a form of COP (coefficient of Performance). The International standards dictate that EER is greater than a preset value in an energy label as shown here in Figure 4. It is classified in efficiency categories from A to G, giving the cooling output at full load in $\mathrm{kW}$ and the energy efficiency ratio in cooling mode at full load.

Countries [21] set their own energy labels based on local industry, energy generation potentials and strategies. The minimum EER in Egypt, for Example is 2.65 for split air conditioners, [22].

The minimum efficiencies of mechanical systems are commonly known as MEPS and are also set to rationalize the energy use in fossil fuel equipment and to reduce the carbon footprint. Assessment of the energy performance of the buildings as a whole are generally through the energy rating systems, an example is the GRPS (green Pyramids Rating System), [23], LEED [24].

The GPRS Green Pyramid Category Weightings are as specified as follows:

1) Sustainable Site, Accessibility and Ecology 10\%;

2) Energy Efficiency 20\%;

3) Water utilization Efficiency 30\%;

4) Materials and Resources $10 \%$;

5) Indoor Environmental Quality 10\%;

6) Management $10 \%$;

7) Innovation and Added Value $10 \%$.

The first group of assessment points go to site and ecology. These were set to encourage development in desert areas, redevelopment in informal areas and avoid projects which negatively affect archaeological, historical and protected areas. This is also to minimize pollution and traffic congestion from car use and to conserve non-renewable energy by encouraging public and alter- native transport. Ultimately this would minimize the environmental impact of the project on the site and its surroundings; to protect existing natural systems, such as fauna and flora (including wildlife corridors and seasonaluses), soil, hydrology and groundwater from damage and to promote biodiversity. 10 points were given for that group, while 20 points for energy efficient building designs utilizing the concepts highlighted here and by Van Dijk et al. [16,17] and Khalil [23]. The Water energy nexus was realized in a 30 point assessment for the water efficiency procedures. Material and resources were given 10 points as well. Indoor environmental quality as

Air conditioners, cooling EER in W/W

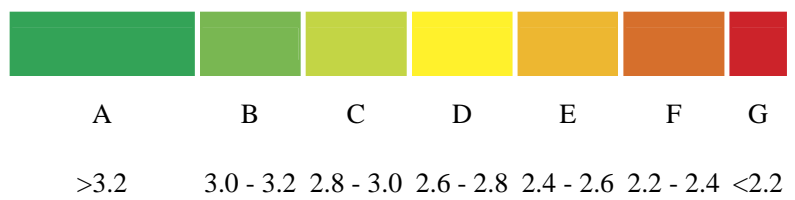

(a)

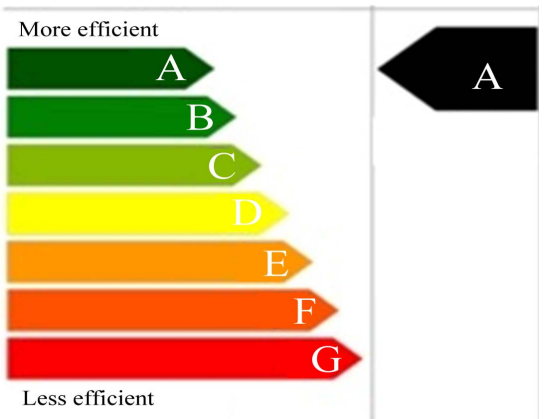

(b)

Figure 4. (a) Energy efficiency ratio classifications for room air conditioners, [21]; (b) Energy efficiency ratio classifications for refrigerators, [21]. 
dedicated by human thermal comfort and acoustics, natural and artificial lighting were given 10 points as well. Proper management and innovation harvest the remaining 20 points. With these rating systems a balance of all the important and influential factors was accounted for. The Building would be certified green if attaining a minimum of 80 points and will be just certified if attaining up to 49 points as indicated in Figure 5.

The final credits are calculated and are categorized within the following rating:

GPRS Certified: 40 - 49 credits;

Silver Pyramid: 50 - 59 credits;

Gold Pyramid: 60 - 79 credits;

Green Pyramid: 80 credits and above.

\subsection{Closure}

As the optimization of the energy consumption is new trend, the achievement of this level needs new investigation trend in the scientific researches. Actually, the energy utilization mainly depends on the optimum utilization of the conditioned air in the conditioned spaces. Sets of common terms, definitions and symbols are essential for all segments from top to bottom.

The target of this work is to highlight procedures to control the alteration, repair, maintenance and operation of existing building sites and the alteration to building site improvements where additions are made to, or changes of occupancy occur within, the existing buildings on the site. Building sites shall be operated and maintainedin conformance with the national green building code. The owner or the owner's designated agent shall be responsible for the operation and maintenance of building sites. The requirements of the green building code shall be incorporated and implemented in new and renovation work. Alterations and repairs to building sites shall comply with the code provisions. Building materials used for building site development shall comply with the re-

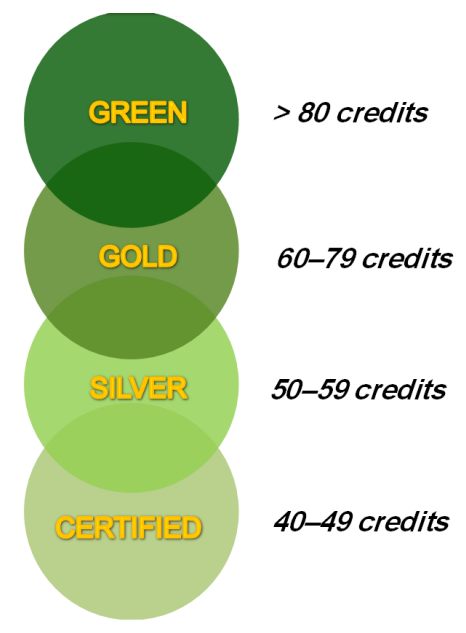

Figure 5. Green building rating system. quirements of the code Materials and systems already in use on a building site in conformance with the requirements or approvals in effect at the time of their installation shall be permitted to remain in use unless determined by the code official to be dangerous to the environment, life, health or safety. Where such conditions are determined to be dangerous to the environment, life, health or safety, they shall be mitigated or made safe.

\section{Acknowledgements}

The author would like to acknowledge the technical support of his colleagues at HBRC and in Particular Prof. Dr. G. B. Hanna, Dr. A. M. Medhat. Author acknowledges the assistance of his colleague Dr. Ramiz Kameel who helped with the analyses.

\section{REFERENCES}

[1] ASHRAE, “ASHRAE Handbook,” Atlanta, 2009.

[2] K. Naydenov, G. Pitchurov, G. Langkilde and A. K. Melikov, "Performance of Displacement Ventilation in Practice,” Proceedings of Roomvent 2002, Copenhagen, 8-11 September 2002, pp. 483-486.

[3] T. S. Jacobsen, R. Hansen, E. Mathiesen, P. V. Nielsen and C. Topp, "Design Method and Evaluation of Thermal Comfort for Mixing and Displacement Ventilation," Proceedings of Roomvent 2002, Copenhagen, 8-11 September 2002, pp. 209-212.

[4] R. Kameel and E. E. Khalil, "Numerical Computations of the Fluid Flow and Heat Transfer in Air-Conditioned Spaces," 35th National Heat Transfer Conference, Anaheim, 10-12 June 2001.

[5] E. E. Khalil, "Thermal Management in Hospitals: Comfort, Air Quality and Energy Utilization,” Proceedings ASHRAE, RAL, Kuwait, October 2009.

[6] Y. Nakamura and A. Fujikawa, "Evaluation of Thermal Comfort and Energy Conservation of an Ecological Village Office,” Proceedings of Roomvent 2002, Copenhagen, 8-11 September 2002, pp. 413-416.

[7] ASHRAE, Applications, 2007, ASHRAE, Atlanta.

[8] ASHRAE Standards 55-2010, ASHRAE, Atlanta.

[9] S. Holmberg and G. Einberg, "Flow Behaviour in a Ventilated Room-Measurements and Simulations," Proceedings of Roomvent 2002, Copenhagen, 8-11 September 2002, pp. 197-200.

[10] S. P. Corgnati, G. V. Fracastoro and M. Perino, "Influence of Cooling Strategies on the Air Flow Pattern in an Office with Mixing Ventilation,” Proceedings of Roomvent 2002, Copenhagen, 8-11 September 2002, pp. 165168.

[11] Y. Cho and H. B. Awbi, "Effect of Heat Source Location in a Room on the Ventilation Performance,” Proceedings of Roomvent 2002, Copenhagen, 8-11 September 2002, pp. 445-448.

[12] Y. Liu and A. Moser, "Airborne Particle Concentration Control for an Operating Room,” Proceedings of Room- 
vent 2002, Copenhagen, 8-11 September 2002, pp. 229232.

[13] R. Kameel, "Computer Aided Design of Flow Regimes in Air-Conditioned Operating Theatres,” Ph.D. Thesis, Cairo University, Cairo, 2002.

[14] R. Kameel and E. E. Khalil, "Prediction of Flow, Turbulence, Heat-Transfer and Air Humidity Patterns in Operating Theatres,” Proceedings of Roomvent 2002, Copenhagen, 8-11 September 2002, pp. 69-72.

[15] R. Kameel and E. E. Khalil, "Prediction of Turbulence Behaviour Using k-Model in Operating Theatres," Proceedings of Roomvent 2002, Copenhagen, 8-11 September 2002, pp. 73-76.

[16] D. Van Dijk and E. E. Khalil, "Energy Efficiency in Buildings,” ISO Focus, 2009, pp. 16-20.

[17] D. Van Dijk and E. E. Khalil, "Future Cities-Building on Energy Efficiency,” ISO Focus, 2011, pp. 25-27.

[18] E. E. Khalil, "Ventilation of the Archaeological Tombs of the Valley of Kings, Luxor, Egypt," Proceedings of In- ternational Conference on Air-Conditioning \& Refrigeration, Korea, 6-8 July 2011.

[19] E. E. Khalil, “Ten Tips for Energy-Efficient Air-Conditioned Buildings,” Proceedings of DETC, ASME International Design Engineering Technology Conference, Montreal, 15-18 August 2010, pp. 733-739.

[20] E. E. Khalil, A. A. Medhat, S. M. Morkos and M. Y. Salem, "Applications of Neural Network in Predicting Energy Consumption in Administrative Buildings," submitted to ASHRAE Annual Meeting, January 2012.

[21] European Commission Energy Labelling, 2010.

[22] E. E. Khalil, "International Focus on Emerging Technologies \& Opportunities,” ASME Congress, 2012, Paper No. IMECE2012-94127.

[23] E. E. Khalil, “An International Outlook of Innovative Design of Low Carbon Buildings,” 3rd International Symposium on Low Carbon Buildings, Ningbo, 27-28 October 2012.

[24] US-Green Building Council, 2012. 